\title{
Maternal and perinatal outcomes of dengue in PortSudan, Eastern Sudan
}

\author{
Ishag Adam*1, Ammar M Jumaa², Hagir M Elbashir and Mubarak S Karsany³
}

\begin{abstract}
Aim: To investigate maternal and perinatal outcomes (maternal death, preterm delivery, low birth weight and perinatal mortality) of dengue at PortSudan and Elmawani hospitals in the eastern Sudan.

Method: This was a retrospective Cohort study where medical files of women with dengue were reviewed.

Results: There were 10820 deliveries and 78 (0.7\%) pregnant women with confirmed dengue IgM serology at the mean (SD) gestational age of 29.4(8.2) weeks. While the majority of these women had dengue fever $(46,58.9 \%)$, hemorrhagic fever and dengue shock syndrome were the presentations in $18(23.0 \%)$ and 12, (15.3\%) of these women, respectively. There were $17(21.7 \%)$ maternal deaths. Fourteen (17.9\%) of these 78 women had preterm deliveries and 19 (24.3\%) neonates were admitted to neonatal intensive care unit. Nineteen (24.3\%) women gave birth to low birth weight babies. There were seven (8.9\%) perinatal deaths. Eight (10.2\%) patients delivered by caesarean section due to various obstetrical indications.
\end{abstract}

Conclusion: Thus dengue has poor maternal and perinatal outcomes in this setting. Preventive measures against dengue should be employed in the region, and more research on dengue during pregnancy is needed.

\section{Introduction}

Dengue is the most common mosquito-borne infection, with an estimated 100 million infections worldwide per year [1-3]. Many factors like urbanization, increased population density, air travel, and limited resources for dengue prevention has led to dengue becoming a major public health problem in the tropics [3]. Of the 100 million annual infections, 250-500 thousand persons manifest severe disease, with the remainder being mild, nonspecific, or even asymptomatic [1-3].

Classic dengue fever (DF) is defined by the World Health Organization as an acute febrile illness with two more of the following signs or symptoms: intense headache, retro-orbital pain, myalgia, arthralgia, rash, leucopenia, and a hemorrhagic manifestation [4]. A small proportion of infected persons develop (dengue hemorrhagic fever (DHF), which is characterized by fever, thrombocytopenia, hemorrhagic manifestations, and increased vascular permeability with plasma leakage primarily into the pleural cavity and peritoneum [5]. The main clinical feature differentiating DF from DHF and

* Correspondence: ishagadam@hotmail.com

1 Faculty of Medicine, University of Khartoum, Khartoum, Sudan

Full list of author information is available at the end of the article dengue shock syndrome (DSS) is the increased vascular permeability, which, if unrecognized or not judiciously treated may result in hypovolemic shock, organ impairment, and death [6].

Dengue during pregnancy may be associated with various complications, including maternal mortality, preterm delivery, fetal death, low birth weight, neonatal admissions, fetal anomalies, and miscarriage [7-14]. However, the vast majority of these reports were case series and from south East Asia. Thus, there is an urgent need to investigate the presentation and outcomes of dengue so as to provide caregivers and health planners with fundamental data necessary for the practicing clinicians as well as researchers.

Dengue have been reported in different regions of the Sudan - which the largest African country - including the study area PortSudan $[15,16]$. Despite the prevalence of dengue in Sudan, there are no data on the maternal and fetal consequences of dengue during pregnancy. The present study was conducted to investigate maternal and perinatal outcomes of dengue infection at PortSudan and Elmawani maternity hospitals in the eastern Sudan. 


\section{Methods}

All dengue cases presented at PortSudan and Elmawani hospitals during 2008 - 2009 were reviewed retrospectively. These two maternity hospitals provide tertiary care for women who receive antenatal care at the hospital, as well as for referrals from other clinics and hospitals, and for women who live close to the hospital facility. All women with risk factors or obstetric complications are referred to this hospital. However, the referral criteria are not strictly adhered to and many patients without any significant complications presented at the hospital.

The medical files of all women with dengue were reviewed; patients' records retrieved and the age, parity, residence, gestational and maternal and perinatal outcomes and biochemical characteristics were recorded. Following our previous collaborations with Sudanese national ministry of health in the different epidemics $[17,18]$ we have been consulted during this dengue epidemic and the diagnosis or exclusion of dengue was conducted in the epidemiological lab in Khartoum under supervision of one of our team (MSK).

A maternal death was defined as the death of a woman while pregnant or within 42 days of termination of pregnancy, irrespective of the duration and site of the pregnancy, from any cause.

Miscarriage was defined as the expulsion of the fetus before 28 weeks of gestation, and preterm delivery as a delivery that occurred between 28 and 37 weeks of pregnancy. Low birth weight is the baby delivered weighting $<2500 \mathrm{gm}$. Perinatal mortality was defined as the number of deaths of newborns born after $\geq 28$ weeks of gestation till the end of day 7 .

\section{Statistics}

Data were entered into a computer database and SPSS software (SPSS Inc., Chicago, IL, USA, version 13.0) and double checked before analysis. Values are reported as frequency, percentage, and mean (SD).

\section{Results}

During the period of study there were 10820 deliveries and $78(0.7 \%)$ pregnant women with confirmed dengue serology IgM using ELISA at the mean (SD) gestational age of 29.4(8.2) weeks. While the majority of these cases were dengue fever $(46,58.9 \%)$, hemorrhagic fever and dengue shock syndrome were the presentations in (18, $23.0 \%)$ and (12,15.3\%), respectively. The socio-demographic characteristics were shown in table 1. Various symptoms were observed among these patients including headache, fever, muscle pain or arthralgia, abdominal pain, retro-orbital pain and rash. Five (6.4\%) and three (3.8\%) patients had vaginal bleeding and epistaxis, respectively.
Table 1: Baseline socio-demographic and biochemical characteristics of the 78 pregnant patients with dengue

\begin{tabular}{|c|c|}
\hline Characters & Mean (SD) \\
\hline Age, years & $28.9(6.8)$ \\
\hline Parity & $2.8(2.3)$ \\
\hline Duration of illness & $5.6(2.3)$ \\
\hline Weight, kg & $62(6.8)$ \\
\hline Gestational age & $29.4(8.2)$ \\
\hline Temperature & $37.8(0.8)$ \\
\hline Haemoglobin, gm/dl & $7.9(2.7)$ \\
\hline Blood glucose, mg/dL & $121.5(8.9)$ \\
\hline Creatinine, $\mathrm{mg} / \mathrm{dL}$ & $1.4(0.6)$ \\
\hline Platelets, cells $/ \mu \mathrm{L}$ & $128,568(18.225)$ \\
\hline White blood cells, cells $/ \mu \mathrm{L}$ & $3425(4565.7)$ \\
\hline Total protein, $\mathrm{g} / \mathrm{dL}$ & $7.8(0.78)$ \\
\hline Serum bilirubin, $\mathrm{mg} / \mathrm{dL}$ & $1.2 \pm 0.9$ \\
\hline $\begin{array}{l}\text { Alanine aminotransferase, } \\
\text { IU/L }\end{array}$ & $65.9 \pm 21.7$ \\
\hline $\begin{array}{l}\text { Aspartate aminotransferase, } \\
\text { IU/L }\end{array}$ & $82.6 \pm 19.5$ \\
\hline
\end{tabular}

There were $17(21.7 \%)$ maternal death due to multiple organ failure and haemorrhage; all of these deaths were dengue hemorrhagic fever and dengue shock syndrome. Fourteen (17.9\%) of these 78 women had preterm deliveries and $19(24.3 \%)$ neonates were admitted to neonatal intensive care unit. Nineteen (24.3\%) women gave birth to low birth weight babies. There was no fetal anomaly. There were seven $(8.9 \%)$ perinatal deaths. Eight $(10.2 \%)$ patients delivered by caesarean delivery due to various obstetrics indications, table 2.

\section{Discussion}

Perhaps this is largest study investigated maternal and perinatal outcomes of dengue during pregnancy. The main findings of this study were the poor maternal and perinatal outcomes due to dengue mainly maternal deaths (21.7\%) and preterm deliveries (24.3\%). We recently reported a high maternal mortality in different regions of Sudan due to various infectious diseases $[19,20]$ for example four $(4.9 \%)$ out of 42 and $25 \%$ of the sixteen women died due to visceral leishmaniasis and viral hepatitis, respectively $[17,21]$. However, in Sudan, as in many sub-Saharan countries, the frequency rates of miscarriage, preterm labor, and congenital abnormalities in the general population are unknown. In Malaysia, out of 16 patients with dengue, there were three cases of maternal death, $50.0 \%$ of the women had preterm deliveries and three babies required intensive care [9]. Previously, it have been reported that maternal clinical dengue 
Table 2: Maternal and perinatal outcomes in 78 pregnant patients with dengue

\begin{tabular}{lll}
\hline Variable & Number & Percentage \\
\hline Maternal death & 17 & 21.7 \\
Low birth weight deliveries & 19 & 24.3 \\
Preterm delivery & 14 & 17.9 \\
Cesarean delivery & 8 & 10.2 \\
Admission to neonatal & 19 & 24.3 \\
intensive care unit & & \\
Perinatal death & 7 & 8.9 \\
\hline
\end{tabular}

may be associated with pregnancy complications, including maternal mortality, preterm delivery, fetal death, low birth weight, neonatal admissions, fetal anomalies, and miscarriage [7-14]. These reports should be compared with ours cautiously, because in this setting we might have observed the severe form of the disease. In contrast to other Asiatic countries, dengue is not endemic in Sudan and epidemics occur from time to another, which explains the lack of immunity in the population and the severity of the disease. Hyperendemic conditions are associated with an increased probability of secondary infections and occurrence of virulent strains. Despite these trends, little research has been conducted to examine the impact of the severity of maternal dengue infection. This is an important factor to assess because viral titers are thought to vary by severity of infection, and pathogenesis associated with poor pregnancy outcomes can be caused by either the direct effect of the virus or the body's response to high titers [22-24]. On the other hand there were no any significant differences in pregnancy outcome comparing dengue IgM-positive with IgM-negative women, perhaps in mild or asymptomatic dengue in pregnant women [25]. However, our study was a hospitalbased one which might not reflect what was at the community level.

In the current study, 5 (6.4\%) patients had vaginal bleeding and $8(10.2 \%)$ patients delivered by caesarean delivery. The risk of maternal haemorrhage was reported before when caesarean section was carried out on patient with dengue fever [14]. Furthermore, difficulties in maintaining haemostasis during the caesarean section were observed too [14]. Deliveries were sometimes pathological, so the risk of haemorrhage has to be assessed and precautions should be taken both for natural delivery and caesarean section. Generally in tropics the situations sometimes are not clear and many infections/toxicity may mimic the obstetrical emergency for example we recently observed association between antepartum haemorrhage and snake bite [26].The impact of dengue on pregnancy is not fully understood. Studies in the litera- ture are limited and case studies were too small to draw conclusions.

\section{Conclusion}

Thus dengue has poor maternal and perinatal outcomes in this setting. Preventive measures against dengue should be employed in the region, and more research on dengue during pregnancy is needed.

\section{Conflicts of interest statement}

The authors declare that they have no competing interests.

\section{Funding}

The study was funded by Pharma Xir, Khartoum, Sudan.

\section{Ethics}

The study received ethical clearance from the Research Board at the Faculty of Medicine, University of Khartoum, Sudan.

\section{Authors' contributions}

IA, HME and MSK designed the study; AM, HME and IA carried out the clinical work and analysis and interpretation of these data. All authors read and approved the final manuscript.

\section{Author Details}

1 Faculty of Medicine, University of Khartoum, Khartoum, Sudan, 2Faculty of Medicine, Red Sea University, PortSudan, Sudan and 'Faculty of Medicine, Juba University, Khartoum, Sudan

Received: 13 June 2010 Accepted: 13 July 2010

Published: 13 July 2010

\section{References}

1. Deen JL, Harris E, Wills B, Balmaseda A, Hammond SN, Rocha C, Dung NM, Hung NT, Hien TT, Farrar JJ: The WHO dengue classification and case definitions: time for a reassessment. Lancet 2006, 368:170-3.

2. Wilder-Smith A, Schwartz E: Dengue in travelers. N Engl J Med 2005 353:924-32.

3. Gibbons RV, Vaughn DW: Dengue: an escalating problem. BMJ 2002, 324:1563-6.

4. World Health Organization: Dengue Haemorrhagic Fever: Diagnosis, Treatment, Prevention and Control. 2nd edition. World Health Organization, Geneva, Switzerland; 1997.

5. Center for Disease Control and Prevention 2008: Chapter 4: Dengue Fever. Yellow Book Traveler's Health 2008 [http://wwwn.cdc.gov/travel/ yellowBookCh4-DengueFever.aspx]. [updated 2008 Jul 29]. Accessed October 28, 2008

6. Rigau-Pérez JG, Clark GG, Gubler DJ, Reiter P, Sanders EJ, Vorndam AV: Dengue and dengue hemorrhagic fever. Lancet 1998, 352:971-977.

7. Carles $G$, Peiffer $H$, Talarmin A: Effects of dengue fever during pregnancy in French Guiana. Clin Infect Dis 1999, 28:637-40.

8. Waduge R, Malavige GN, Pradeepan M, Wijeyaratne CN, Fernando S, Seneviratne SL: Dengue infections during pregnancy: a case series from Sri Lanka and review of the literature. J Clin Virol 2006, 37:27-33.

9. Ismail NA, Kampan N, Mahdy ZA, Jamil MA, Razi ZR: Dengue in pregnancy. Southeast Asian J Trop Med Public Health 2006, 37:681-3.25.

10. Carles G, Talarmin A, Peneau C, Bertsch M: Dengue fever and pregnancy. A study of 38 cases in french Guiana [in French]. J Gynecol Obstet Biol Reprod 2000, 29:758-62.26.

11. Malhotra N, Chanana C, Kumar S: Dengue infection in pregnancy. Int J Gynaecol Obstet 2006, 94:131-2. 
12. Sharma JB, Gulati N: Potential relationship between dengue fever and neural tube defects in a northern district of India. Int J Gynaecol Obstet 1992, 39:291-5.

13. Watanaveeradej V, Endy TP, Samakoses R, Kerdpanich A, Simasathien S, Polprasert N, Aree C, Vaughn DW, Ho C, Nisalak A: Transplacentally transferred maternal-infant antibodies to dengue virus. Am J Trop Med Hyg 2003, 69:123-8.

14. Pouliot SH, Xiong X, Harville E, Paz-Soldan V, Tomashek KM, Breart G, Buekens P: Maternal dengue and pregnancy outcomes: a systematic review. Obstet Gynecol Surv 2010, 65:107-18.

15. McCarthy MC, Haberberger RL, Salib AW, Soliman BA, El-Tigani A, Khalid IO, Watts DM: Evaluation of arthropod-borne viruses and other infectious disease pathogens as the causes of febrile illnesses in the Khartoum Province of Sudan. J Med Virol 1996, 48:141-6.

16. Ageep AK, Malik AA, Elkarsani MS: Clinical presentations and laboratory findings in suspected cases of dengue virus. Saudi Med J 2006, 27:1711-3.

17. Ahmed RE, Karsany MS, Adam I: Brief report: acute viral hepatitis and poor maternal and perinatal outcomes in pregnant Sudanese women. J Med Virol 2008, 80:1747-8.

18. Adam AA, Karsany MS, Adam I: Manifestations of severe Rift Valley fever in Sudan. Int J Infect Dis 2010, 14:179-80.

19. Haggaz AA, Radi EA, Adam I: High maternal mortality in Darfur, Sudan. Int J Gynecol Obstet 2007, 98:252-3.

20. Elhassan ME, Mirgahani OA, Adam I: Maternal mortality and stillbirth in central Sudan. Tropical Doctor 2009, 39:238-9.

21. Adam GK, Abdulla MA, Ahmed AA, Adam I: Maternal and perinatal outcomes of visceral leishmaniasis (kala-azar) treated with sodium stibogluconate in eastern Sudan. Int J Gynaecol Obstet 2009, 107:208-10,

22. Ventura A, Ehrenkranz N, Rosenthal D: Placental passage of antibodies to dengue virus in persons living in a region of hyperendemic dengue virus infection. J Infect Dis 1975, 131:62-68.

23. Vaughn DW, Green S, Kalayanarooj S, Innis BL, Nimmannitya S, Suntayakorn S, Endy TP, Raengsakulrach B, Rothman AL, Ennis FA, Nisalak $A$ : Dengue viremia titer, antibody response pattern, and virus serotype correlate with disease severity. J Infect Dis 2000, 181:2-9.

24. Endy TP, Nisalak A, Chunsuttitwat S, Vaughn DW, Green S, Ennis FA, Rothman AL, Libraty DH: Relationship of preexisting dengue virus (DV) neutralizing antibody levels to viremia and severity of disease in a prospective cohort study of DV infection in Thailand. J Infect Dis 2004, 189:990-1000.

25. Tan PC, Rajasingam G, Devi S, Omar SZ: Dengue infection in pregnancy: prevalence, vertical transmission, and pregnancy outcome. Obstet Gynecol 2008, 111:1111-7.

26. Adam I, Gerais AS: Abruptio placentae following snake bite in a Sudanese woman. Saudi Med J 2005, 26:686-7.

doi: 10.1186/1743-422X-7-153

Cite this article as: Adam et al., Maternal and perinatal outcomes of dengue in PortSudan, Eastern Sudan Virology Journal 2010, 7:153

Submit your next manuscript to BioMed Centra and take full advantage of:

- Convenient online submission

- Thorough peer review

- No space constraints or color figure charges

- Immediate publication on acceptance

- Inclusion in PubMed, CAS, Scopus and Google Scholar

- Research which is freely available for redistribution

Submit your manuscript at www.biomedcentral.com/submit
C Biomed Central 